Article

\title{
The Influence of Clay Content on Cave-ins in Tank Model Tests and Monitoring Indicators of Sinkhole Formation
}

\author{
Sueng-Won Jeong *, Byoung-Woo Yum, Dong-Woo Ryu, Hong-Jin Lee and Byeongju Jung \\ Korea Institute of Geoscience and Mineral Resources, Daejeon 34132, Korea; ybw@kigam.re.kr (B.-W.Y.); \\ dyryu@kigam.re.kr (D.-W.R.); leehj@kigam.re.kr (H.-J.L.); bjung@kigam.re.kr (B.J.) \\ * Correspondence: swjeong@kigam.re.kr; Tel.: +82-42-868-3911
}

Received: 23 April 2019; Accepted: 4 June 2019; Published: 7 June 2019

\begin{abstract}
Urban cave-ins may result from a sudden change in local hydrological, hydrogeological and anthropogenic conditions. Monitoring and predicting urban sinkholes is not straightforward, and solving the problem of urban cave-ins involves the incorporation of the fields of geodetics, geophysics and geochemistry. This paper examines the causes and consequences of sinkholes in sand-rich materials by using a small tank model apparatus. Tank model tests were conducted to simulate sinkhole formation, to gain a better understanding of the influencing factors of cavity formation, expansion and upward migration with different cavity water levels. Two commercial materials were used: Jumunjin sand and kaolinite clay. Materials with different grain-size distributions, i.e., sand (100\% Jumunjin sand) and sand-clay mixtures ( $95 \%$ sand and $5 \%$ kaolinite clay), were considered to examine the roles of clay content in sinkhole risk. The test results show that the sand-rich materials exhibited a typical punching type of sinkhole subsidence and failure, and were very sensitive to changes in groundwater level, regardless of the grain-size distribution. The higher the groundwater level is, the higher the sinkhole risk is in terms of the speed of migration of the underground cavity fluids, cavity size and ground loosening. Therefore, sinkholes in urban areas covered with sand-rich materials are vulnerable to groundwater withdrawal. However, compared with pure sand, materials with small clay contents can reduce the time until collapse and the size of a sinkhole. Variations in pore water pressure may be used as a sinkhole indicator in areas where the ground deformation caused by groundwater depletion is considerable.
\end{abstract}

Keywords: cave-in; sinkhole; tank model test; groundwater level; clay content

\section{Introduction}

Urban sinkholes pose considerable threats to people and property because these cavities might develop underground without notice [1,2]. An aged and damaged sewer pipe may cause local subsidence and sudden surface collapse in urban areas, especially along roads [2]. These events may be related to the age of the infrastructure; insufficient proactive management may induce cave-ins in urban areas. Sudden surface collapse in urban areas can also occur around construction work due to unreliable groundwater management around soil foundations or civil infrastructures. Sinkhole classification and case histories in karst and cavernous rocks in engineering practice have been examined by numerous studies [3-6]. Sinkholes can also form in volcanic sandy deposits [7]. A proper monitoring system should be developed to minimize catastrophic urban sinkholes. To develop a proper monitoring system, sinkhole mechanisms and influencing factors are first examined in terms of disaster prevention and mitigation measures. Many sinkhole studies have been previously performed with respect to sinkhole prediction using synthetic aperture radar (SAR)-related imagery data [8-10], 
geophysical approaches [11-13] and geophysical modeling [1,14]. In particular, it is well known that interferometric synthetic aperture radar (InSAR) monitoring and light detection and ranging (LiDAR) measurements are effective early warning techniques which enable the detection of ground subsidence before the catastrophic sinkholes [15-18].

In physical experimental approaches, numerous works have been performed to gain a better understanding of sinkhole mechanisms in sand-rich materials, because cave-ins are often observed in roads overlying areas backfilled with sand-rich materials. Therefore, soil compaction and water management are very important issues in the field of urban sinkholes. In addition, the grain-size distribution may be very important, because the clay content in sinkhole materials is also related to the loss of small particles, e.g., the loss of clay content in fine-grained sediments in permeable soil may create water pathways and reduce the soil strength [19]. However, the influence of grain size on sinkhole formation, especially the role of clay content, is poorly understood. In this paper, sinkhole formation is examined with respect to sand and sand-clay mixtures, using a small tank model apparatus. In addition, a proper technique to monitor the occurrence of sinkholes is suggested, based on test results.

The objectives of this paper are to examine the cavity development and sinkhole monitoring factors in sand (100\% Jumunjin sand) and sand-clay (95\% sand and $5 \%$ clay) mixtures. To determine a proper monitoring system in urban areas, a simple technique is used to simulate the sinkhole. A series of small tank model tests, which can simulate cavity expansion and surface collapse by the repeated inflow and outflow of soil-water mixtures, was performed to understand the sinkhole triggering mechanisms and their consequences. Regarding the sinkhole indicators, variations in the pore water pressure, volumetric water content, electrical conductivity and temperature during cavity development are examined with respect to the cavity expansion and surface collapse in the tank model. However, the soil-water interactions between a buried structure and the ground are beyond the scope of this study.

\section{Materials and Methods}

\subsection{Materials}

The materials used in the tank model were commercial Jumunjin sand and kaolinite clay. Jumunjin sand is known as typical standard sand in Gangneung, Republic of Korea. The geotechnical properties of Jumunjin sand are as follows: specific gravity $\left(G_{s}\right)=2.65$, medium grain size $\left(D_{50}\right)=0.6 \mathrm{~mm}$, uniformity coefficient $\left(C_{\mathrm{u}}\right)=1.5$ and maximum and minimum void ratio $=0.84$ and 0.61 , respectively. Two materials were considered to examine the influence of clay content on sinkhole risk: $100 \%$ Jumunjin sand and a sand-clay mixture with $95 \%$ Jumunjin sand and 5\% kaolinite. Jumunjin sand is typically used for studying the engineering behavior of sand in Korea, similar to Toyora sand in Japan. In the text, sand refers to 100\% Jumunjin sand, and sand-clay mixture refers to $95 \%$ Jumunjin sand and $5 \%$ kaolinite clay.

\subsection{Methods}

The test apparatus was designed to simulate cavity expansion and to observe surface collapse (Figure 1). There are three chambers in the test apparatus: a ground (or soil) chamber in the middle section, containing the soil samples, and groundwater level control chambers (water chambers), which are located on both sides of the ground chamber (Figure 1a). The dimensions of the tank are $300 \times 200 \times 50 \mathrm{~mm}$. Each water chamber was $50 \mathrm{~mm}$ long and $200 \mathrm{~mm}$ high, and included permeable porous ceramics. The permeable porous ceramic filter plates are located between the ground and water chambers (Figure 1a). Thus, water is able to move only through the porous filter. The tank model was made of a transparent acrylic plate for visual observation of the cavity expansion during the inflow and outflow cycles of the soil and water. The cavity can form at the bottom of the soil chamber by opening a drainage valve which is $5 \mathrm{~mm}$ in diameter (Figure 1b). A constant amount of water (i.e., $200 \mathrm{~cm}^{3}$ ) 
was supplied from the water tank. The opening valve was opened after $60 \mathrm{~min}$, and a cycle of water supply and soil and water drainage is considered due to the breakage of sewer pipes in urban areas. The inflow and outflow cycles were repeated until surface collapse was observed. The same procedure was applied for different groundwater levels.

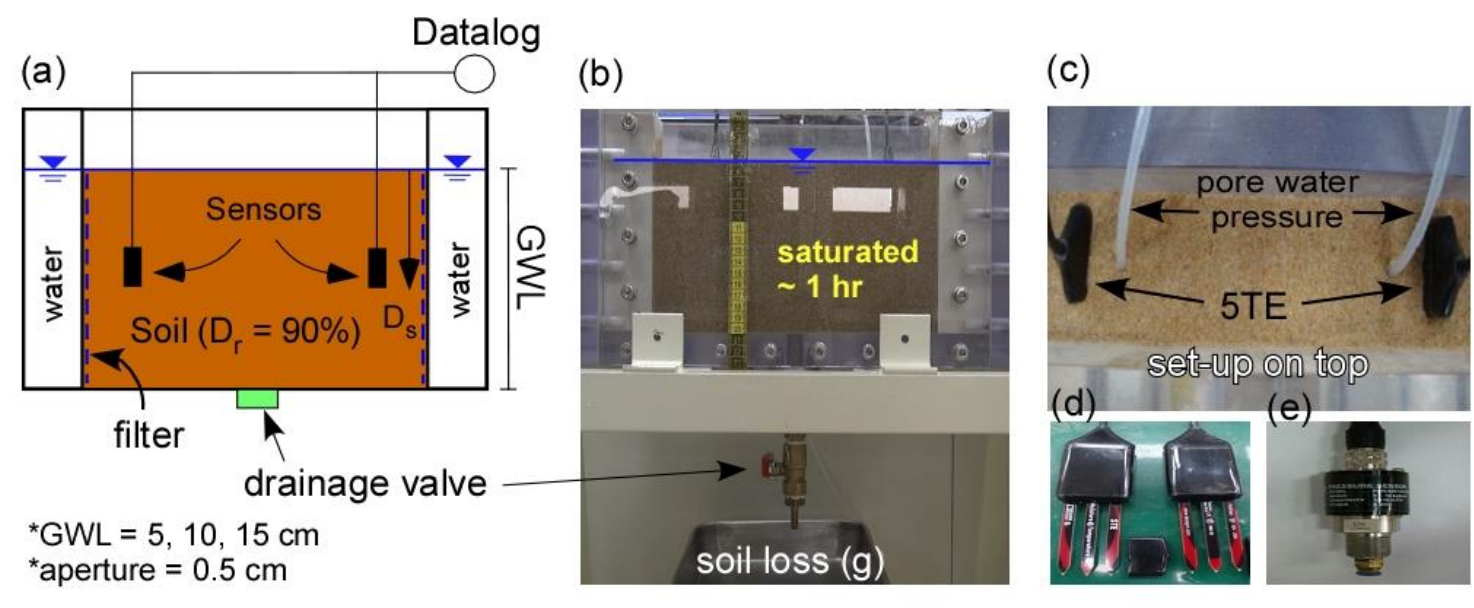

\section{(f) Sand $100 \%$}

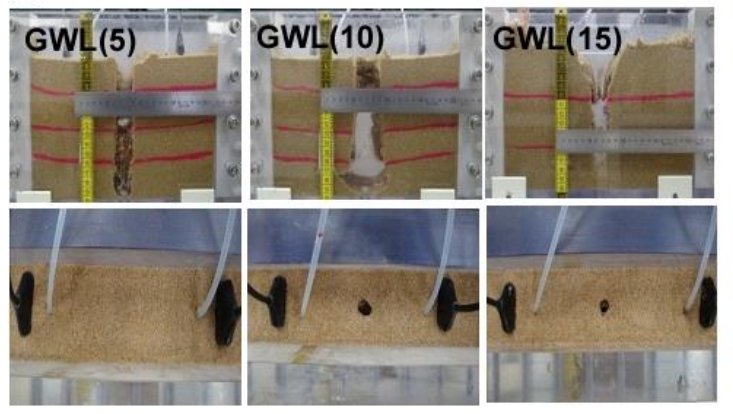

(g) Sand $95 \%+$ Clay $5 \%$

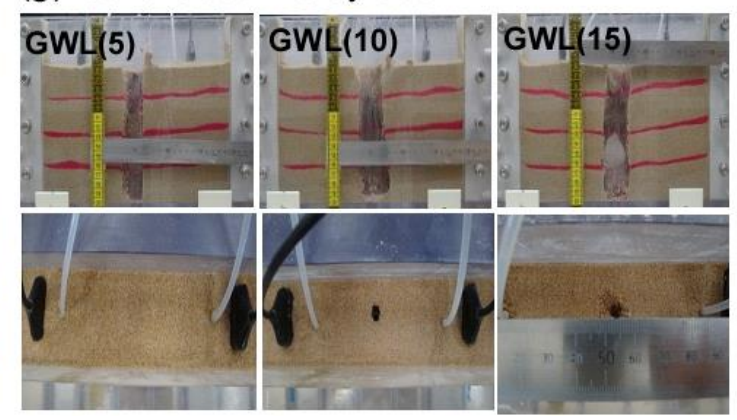

Figure 1. Tank model apparatus: (a) model diagram with sensors; (b) saturation; (c) setup; (d) sensor (called 5TE) designed to measure electrical conductivity, temperature and water content; (e) pore water pressure sensor; (f) sand; (g) sand-clay mixture. Figure 1f,g show significant punching failure type for water levels of 10 and $15 \mathrm{~cm}$ high.

The soil samples filled the ground chamber, and the soil was added in layers. Each soil layer was compacted manually to a thickness of $1 \mathrm{~cm}$. Colored soil layers with a thickness of $5 \mathrm{~cm}$ were placed in each tank model, in order to allow easier observation of the ground deformation and wetting in the front and rear of the tank model. The water level in the tank model is regulated to be 5, 10 and $15 \mathrm{~cm}$ high at a fixed relative density of the soil sample (i.e., 90\%). The water for the saturation and adjusted groundwater levels was supplied into the ground model from the bottom of the plate using the minimum inflow rate $(\leq 0.1 \mathrm{~mm} / \mathrm{s})$, without any sample disturbance. Then, the drainage valve was opened. The weight of the soil and water flowing out of the tank was measured. According to the previous research of Kuwano et al. [20], the overburden load in the ground tank is not a significant influencing factor in the process of cavity and sinkhole formation. Therefore, in this study, the overburden load is not considered. A high-quality and easy-to-use camera was used to record images of the ground deformation during the test. Variations in pore water pressure, volumetric water content, electrical conductivity and temperature are considered as sinkhole indicators. Sensors were placed in the ground model, at $8 \mathrm{~cm}$ from the surface (Figure 1). 


\section{Results}

\subsection{Variations in Groundwater Level and Sinkhole Occurrence}

A series of small-scale laboratory tank model experiments was performed to examine the influence of clay content on sinkhole characteristics of sand-rich materials. It is well known that cavity development and surface collapse are dependent on soil density and variations in groundwater levels [20]; the variation in groundwater level is one of the main triggering factors in sinkhole formation. Even for the same density of sandy soil, the variation in groundwater level could impact the sinkhole risks in terms of the upward migration of the underground cavity, sinkhole size, influencing zones, and so on (Table 1). In this study, the relative density of the soil sample was fixed (i.e., $D_{\mathrm{r}}=90 \%$ ), and the tested groundwater levels in the ground model were selected to be 5, 10 and $15 \mathrm{~cm}$ high (i.e., low, medium, and high groundwater level) for the two types of soil samples. After the test was complete, the sinkhole characteristics were examined. There was no surface collapse for the soil with a groundwater level of $5 \mathrm{~cm}$. The cavity existed only under the groundwater level; for the lowest groundwater level case (i.e., $5 \mathrm{~cm}$ ), the local surface appeared to subside (i.e., cover-subsidence sinkhole), regardless of the grain size effect. In the tank model, a cavity grew and reached the surface when the drainage valve was opened (Figure 1b).

Table 1. Summary of the test results for the sand and sand-clay mixtures.

\begin{tabular}{ccccccc}
\hline Measurements & \multicolumn{3}{c}{ Sand $\mathbf{1 0 0} \%$} & \multicolumn{3}{c}{ Sand $\mathbf{9 5 \%}+$ Clay $\mathbf{5 \%}$} \\
\hline $\mathrm{GWL}(\mathrm{cm})$ & 5 & 10 & 15 & 5 & 10 & 15 \\
$\mathrm{u}_{\mathrm{f}}(\mathrm{kPa})$ & 0.5 & 1.3 & 2 & 0.6 & 1.6 & 2 \\
$\Delta \mathrm{u}(\mathrm{kPa})$ & 0.1 & 0.6 & 1.1 & 0.2 & 0.6 & 1.33 \\
$\mathrm{t}_{\mathrm{f}}(\mathrm{sec})$ & $50^{*}$ & 60 & 30 & $150^{*}$ & 110 & 100 \\
Surface collapse & $\mathrm{X}$ & $\mathrm{O}$ & $\mathrm{O}$ & $\mathrm{X}$ & $\mathrm{O}$ & $\mathrm{O}$ \\
Cavity $(\mathrm{cm} \times \mathrm{cm})$ & $2.5 \times 10$ & $4 \times 11$ & $4 \times 14$ & - & $3 \times 10$ & $3 \times 13$ \\
Failure type & - & Punching & Punching & - & Punching & Punching \\
Soil loss $(\mathrm{g})$ & 150 & 430 & 560 & 305 & 450 & 565 \\
\hline
\end{tabular}

Note: $\mathrm{GWL}=$ groundwater level; $\mathrm{u}_{\mathrm{f}}=$ pore water pressure at failure; $\Delta \mathrm{u}=$ difference in pore water pressure between the drainage opening and collapse; $\mathrm{t}_{\mathrm{f}}=$ time difference; $\mathrm{O}=$ collapsed; $\mathrm{X}=$ not collapsed; and ${ }^{*}=$ surface subsidence at the end of the test.

Figure 2 presents the test results of the variations in pore water pressure, volumetric water content, electrical conductivity and temperature in Jumunjin sands during sinkhole tests (also see Figure 1d,e. Figure 2a shows the pore water pressure measurements with time, for the groundwater levels (GWLs) of 5, 10 and $15 \mathrm{~cm}$. The downward arrows in Figure 2 indicate the times when the valves were opened for each groundwater level. The open circles indicate the time of the surface collapse. The time required for complete water inflow at a desired groundwater level ranged from 1000 to $1500 \mathrm{~s}$. After the water inflow, the saturation time for the soils in the ground model was approximately 300-800 s. In fact, for the commercial Jumunjin sand, it is expected that the time to reach full saturation is less than $10 \mathrm{~min}$. In the same period, the volumetric water content, electrical conductivity and temperature were measured and reached a steady-state condition; in other words, constant values of these parameters were observed during this period. The detection range was approximately $5 \mathrm{~cm}$ around the sensor. The drainage valve was opened for the compulsory upward migration of the cavity at $1900 \mathrm{~s}(5 \mathrm{~cm})$, $2000 \mathrm{~s}(10 \mathrm{~cm})$ and $2100 \mathrm{~s}(15 \mathrm{~cm})$. As shown in Figure 2a, the pore water pressures reacted almost immediately to the reduction in the water volume in the ground model. In fact, there was a delay between the valve opening and the observation of a sinkhole, e.g., $60 \mathrm{~s}$ for $10 \mathrm{~cm}$ and $30 \mathrm{~s}$ for $15 \mathrm{~cm}$. 

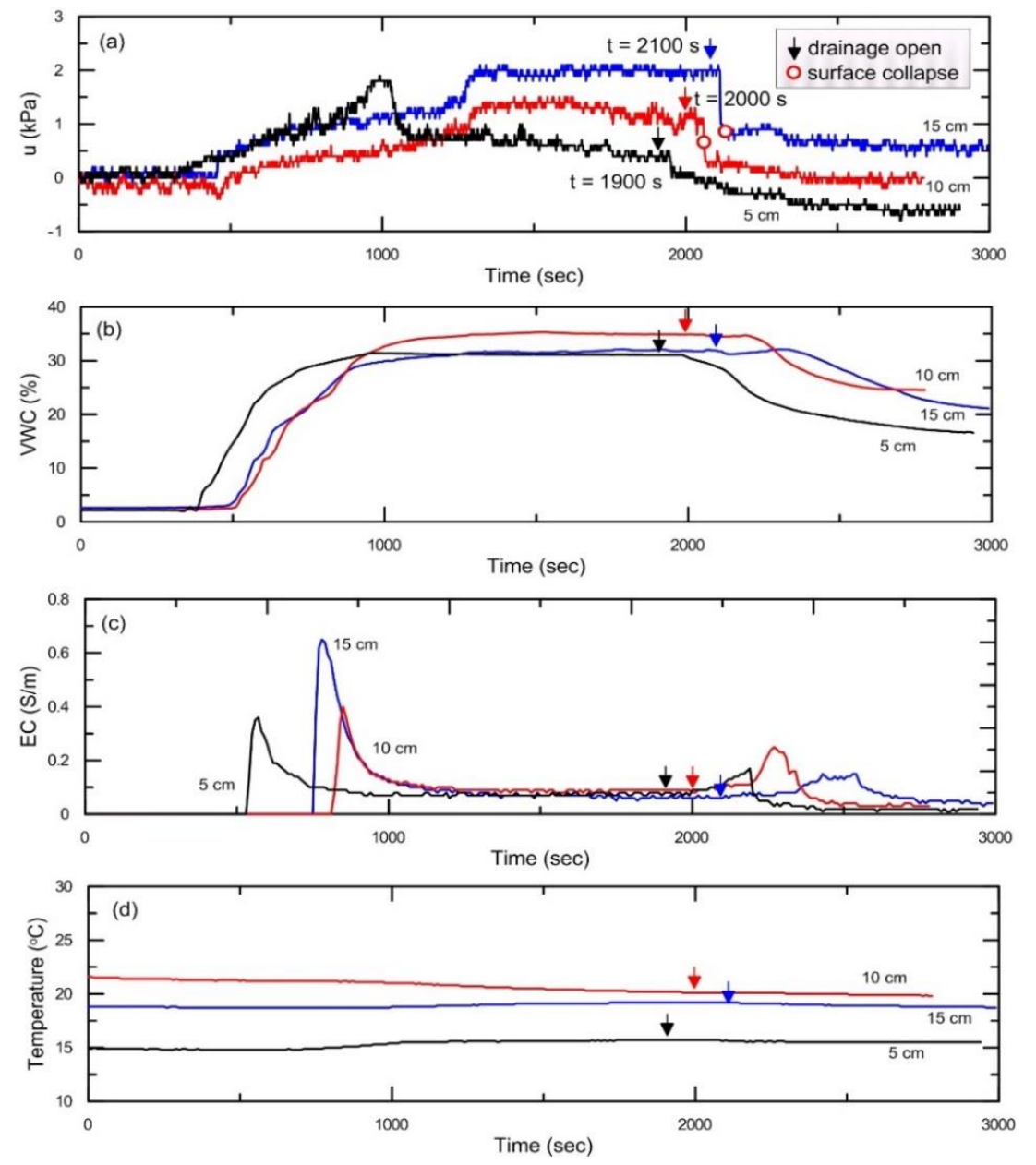

Figure 2. Test results of the variation in groundwater level: (a) pore water pressure; (b) volumetric water content; (c) electrical conductivity; (d) temperature.

Therefore, the higher the groundwater level is, the greater the reduction in pore water pressure. For the highest groundwater level case, the difference was approximately one order of magnitude. Unlike the case of the lowest groundwater level (i.e., $5 \mathrm{~cm}$ ), the surface collapse appeared between 30 and $60 \mathrm{~s}$ after the drainage valves were opened, in the other cases (Figure 1). When the water level was higher than the sensors installed in the ground model, a more rapid decrease in pore water pressure was expected to occur. The differences in pore water pressure varied from 0.5 to $2 \mathrm{kPa}$. In the case of $5 \mathrm{~cm}$, the pore water pressure did not change immediately after the drainage valve was opened. This result potentially occurred because there was a gap between the groundwater level and the location of the installed sensor (i.e., $2 \mathrm{~cm}$ ). Additionally, partially saturated soils, especially sand and/or sand-rich soils, may lead to material bulking at relatively low water contents. In contrast, the volumetric water content, electrical conductivity and temperature seem to be insensitive to the soil outflow during the initial stage of sinkhole formation. In particular, the volumetric water content and temperature gradually decreased with soil outflow (i.e., when the drainage valve opened) from 700 to $1100 \mathrm{~s}$, and the water contents and temperatures varied from approximately from $10 \%$ to $15 \%$ and from 0.2 to $0.5{ }^{\circ} \mathrm{C}$, respectively. Electrical conductivity was always reacted after a considerable time (e.g., $\Delta t=200-500 \mathrm{~s}$ ). This lag may be related to the soil loss with the formation of a water pathway past the sensors. All cases exhibit a punching failure type (i.e., cover collapse sinkhole), regardless of the groundwater level. As expected, the cavity sizes and soil losses increased with increasing groundwater level (Table 1). 


\subsection{Role of Clay Content in Sinkhole Risk}

From the test results, a prompt response against cavity expansion and surface collapse is possible if the pore water pressure is monitored. Thus, it is very clear that the variation in pore water pressure in monitoring urban sinkholes is more applicable than other indicators. The water content, electrical conductivity and temperature changed when the ground materials were deformed. However, although it may be concluded that the sinkhole can influence these properties, the change in these properties was not directly linked to the sinkhole occurrence in the small tank model tests. Therefore, we focused on the coupling between the pore water pressure and indications of sinkhole risk.

Figure 3 presents a comparison of the test results between the Jumunjin sand (100\% sand) and the sand-clay mixture (95\% sand and $5 \%$ clay). Both soil samples are very sensitive to variations in water pressure. There are several differences between the two types of soil samples, e.g., the variations in pore water pressure, time until surface collapse failure, cavity size, and amount of soil loss. Unlike the sand, it takes longer for the sand-clay mixture to become fully saturated (e.g., 1000-3000 s). Figure 3a,c,e show the full timescale of the test results; Figure $3 b, d$, f show selected timescales of the variations in water pressure with time, based on the starting point of soil outflow. Zero along the x-axis $(0 \mathrm{~s})$ is the time when the drainage valve was opened for the same test, and $\Delta \mathrm{u}$ is the variation in the pore water pressure $(\mathrm{kPa})$. Like the sand, the sand-clay mixture undergoes a surface collapse in the 10 and $15 \mathrm{~cm}$ groundwater level tests. The variation in the pore water pressure of the sand-clay mixture is approximately the same or slightly greater than that of the sand. The soil samples have the same response to the variation in groundwater level: the higher the groundwater level, the higher the risk of a sinkhole. It is interesting to note that there is a large difference in the lag between the opening of the drainage valve and the observation of surface collapse. This lag may be used to detect sinkholes during field monitoring. In the tank model tests, the time needed to detect surface collapse in the sand-clay mixture is two to three times longer than in the sand (30-60 s) and sand-clay mixture (100-110 s). The sand-clay mixture can resist large deformation due to an apparent cohesive network in the ground model; thus, the cavity size in the ground model is slighter smaller in the sand than in the sand-clay mixture. Compared to the sinkholes formed in the sand, the sinkholes formed in the sand-clay mixture are smaller (Table 1). Therefore, in a way, the ground, with a larger percent of small particles, is more dangerous because it is difficult to detect cavity formation from the surface. However, the sinkhole risk is greater in sand than in clay; in other words, a small amount of clay in the ground can help to reduce cavity expansion and delay surface collapse. All cases exhibited the punching type of sinkhole failure, regardless of the groundwater level. The cavity sizes and soil losses were also very sensitive to variations in the groundwater level (Table 1). 

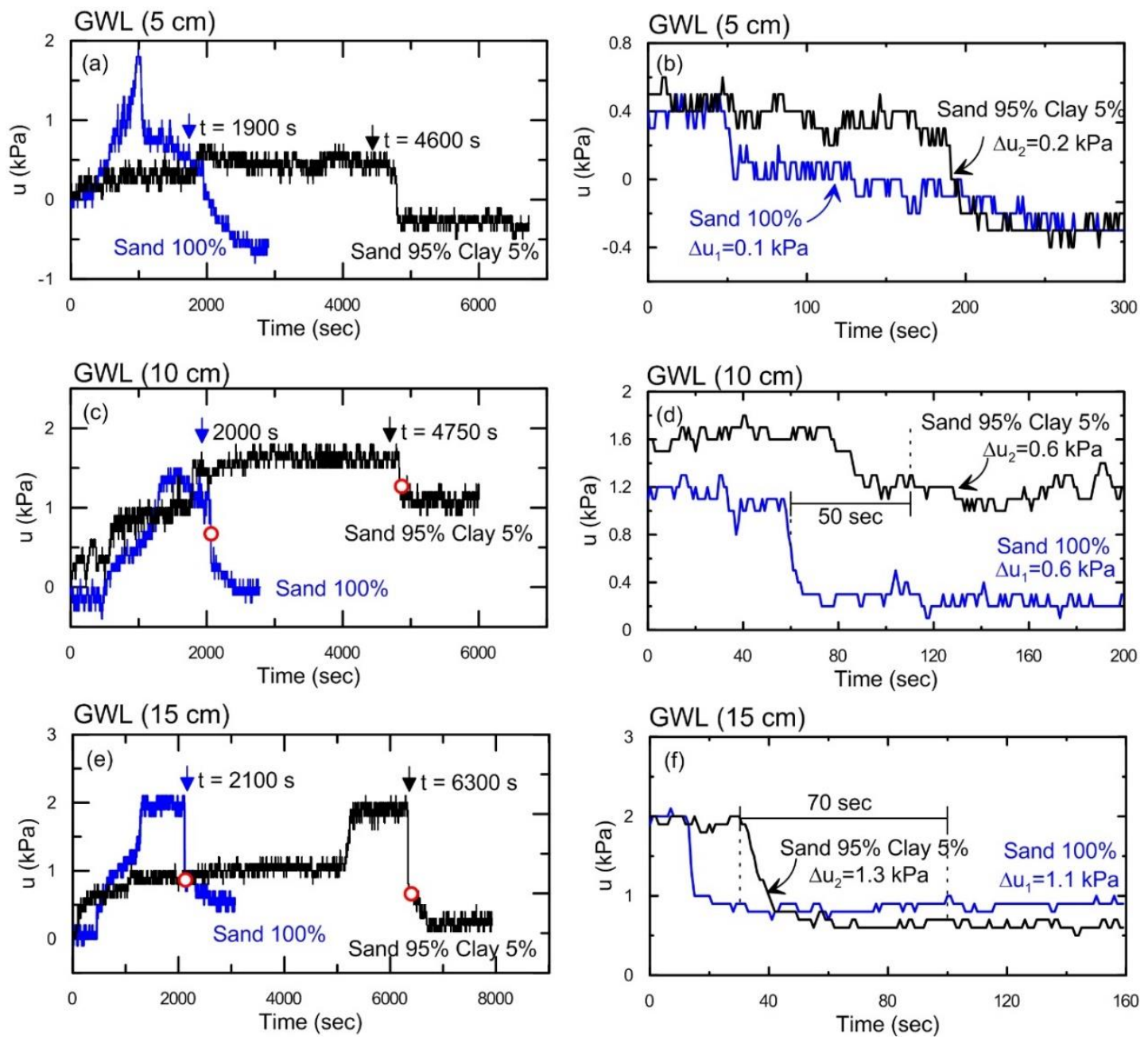

Figure 3. Comparison between the sand and sand-clay mixture results. The arrows indicate the start point of upward migration of the cavity in (a), (c), (e) which is the same as the time of $0 \mathrm{~s}$ in (b), (d), (f). $\Delta \mathrm{u}=$ variation in the pore water pressure $(\mathrm{kPa})$.

Figure 4 presents a summary of the test results of the sinkhole characteristics in sand and sand-clay mixtures, as a function of the variations in the groundwater level in the small tank model tests. Figure 4a shows the relation between the time until failure of the topsoil in the ground model and the groundwater level; the time until failure in both materials gradually decreased with an increase in groundwater level. However, the time until failure is delayed for the soil with clay, and is of the order of two to three times longer. Figure $4 \mathrm{~b}$ presents the reduction in pore water pressure with the groundwater level. Figure $4 \mathrm{c}, \mathrm{d}$ are the observed cavity height and soil loss as a function of the groundwater level. The observed height of the cavity was measured from the bottom of the plate in the ground model. For both materials, the differences in the cavity height and soil outflow were very small at the highest water level; therefore, the ground model was fully saturated (i.e., GWL goes to $15 \mathrm{~cm}$ ). At the lowest water level $(5 \mathrm{~cm})$, however, the sinkhole characteristics are affected by the clay content. The clay content can improve the resistance of the soil to cavity expansion. In Figure $4 b$, the lowest water level may be a typical condition in urban sinkhole-prone areas in Korea (e.g., approximately $7 \mathrm{~m}$ below the ground surface in Daejeon Metropolitan City, Republic of Korea). In addition, the highest water level $(15 \mathrm{~cm})$ is considered for extremely heavy rainfall events. The cavity size and soil loss during the tests are significantly affected by the groundwater level. 

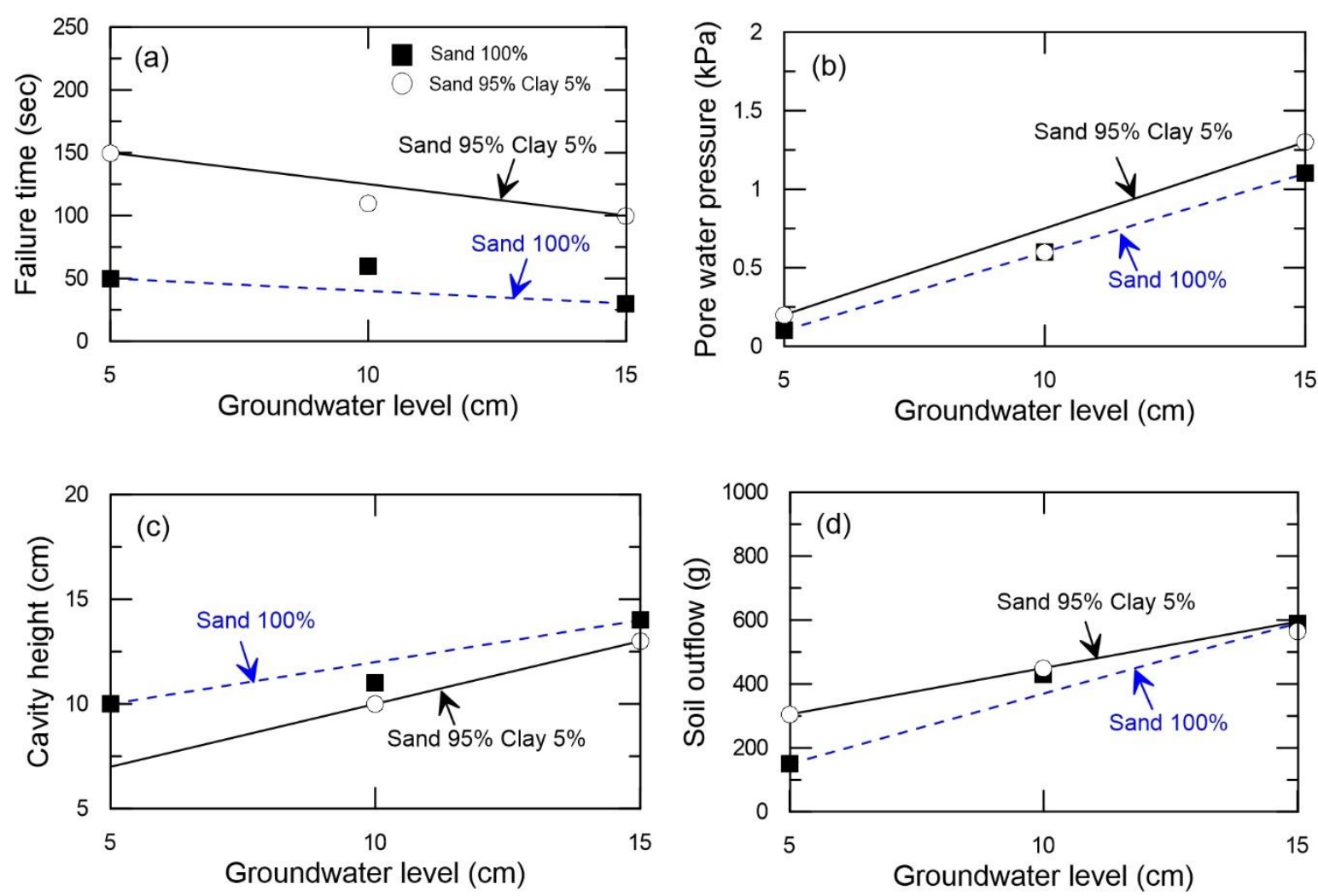

Figure 4. Sinkhole characteristics as a function of clay content: (a) failure time; (b) pore water pressure; (c) cavity height; (d) soil outflow.

To prevent future sinkholes in urbanized areas, the mechanism and consequences of grain-size-dependent sinkhole risk should be established. Recently, for human-induced sinkhole occurrences in Ecuador, Toulkeridis et al. [21] proposed a new risk-management approach, including (1) determining the hydrological and hydrogeological characteristics of sinkhole-prone areas, (2) performing a geotechnical characterization in terms of the material properties and (3) creating accurate monitoring and prevention techniques. To implement this approach, we need a sinkhole database and inventory map. One of the important issues is determining the causes and consequences of urban sinkholes, e.g., the rainfall-induced ground deformation and uncertainties in the migration of the fine content in the soil matrix due to natural causes or the breakage of outdated pipes and insufficient maintenance of underground facilities from artificial environments. Additionally, cavities can form underground due to damaged buried structures, aged sewer pipes, drainage problems surrounding underground tunnels, and deteriorating retaining walls with broken concrete; therefore, these conditions should be considered. In terms of assessing the soundness of civil infrastructures, the corrosion and damage of underground sewer pipes is difficult to determine. In this study, one of the simplest cases was considered. Thus, loosening around the cavity is not easy to determine in a small tank model test. The outflow of fine-grained sediments can be gradually observed during the inflow and outflow cycling in the tank model tests. According to Sato and Kuwano [2], soil and water loss is not as easy in dense conditions, but can easily expand the loose soil conditions. They stressed that the maximum fine loss that can be reached is $50 \%$ of the initial fines in the model ground. In addition, the rate of subsurface erosion in the process of piping is approximately one order of magnitude greater than the surface erosion [22]. In a future study, the infiltration effect on the damage to underground structures and sinkhole occurrence should be examined. Grain deformation and crack mechanisms in sinkholes are crucial. Numerical analysis for predicting future sinkhole events in urban areas may be recommended using grain-based models, such as Particle Flow Code (PFC) and related numerical techniques [23-25]. 


\section{Conclusions}

An underground cavity can form naturally or artificially. The formation of an urban sinkhole is inevitable with time, when an underground cavity forms. Assessing the soundness of infrastructures and the potential risk related to cavity development on a national scale is challenging. Therefore, a proper monitoring system that uses easy and simple methods should be set up to identify the ground deformation associated with sediment and water outflow. This study summarizes a number of experimental results from small-scale laboratory tank model tests. The main conclusions drawn are as follows.

(1) Soil compaction and water level are very important factors in the assessment of sinkhole risks. For the same soil density, the cavities in the sand-rich materials in the small tank model tests expanded and reached the surface more easily, because the sinkhole characteristics were strongly influenced by the groundwater level. The cavities expanded until they reached the groundwater level. All the cases tested showed sensitivity to variations in the groundwater level: the higher the groundwater level is, the higher the risk of a sinkhole, in terms of the speed of upward migration of the underground cavity, the size of the cavity and the influencing zones of the cavity, which include zones of ground loosening.

(2) Sand-rich materials exhibited a typical punching type of sinkhole failure and were vulnerable to changes in the groundwater level. The clay content in the sand-rich materials played a significant role in the sinkhole risk. A small clay content can delay sinkhole occurrence and decrease the size of the cover collapse sinkhole, even for only $5 \%$ clay content in sandy materials.

(3) In the sinkhole monitoring system, continuous measurements may be collected for pore water pressure below the groundwater level, and for suction stress above the groundwater level. Over long periods or during the development of a deep underground cavity, the volumetric water content, electrical conductivity and temperature can be used as secondary ground deformation indicators because they change slowly with deformation, but they do not necessarily indicate ground collapse.

Author Contributions: Conceptualization, S.-W.J., B.J. and B.-W.Y.; methodology, S.-W.J., D.-W.R. and H.-J.L.; data and formal analysis, S.-W.J.; writing—original draft, S.-W.J;; writing—review and editing, S.-W.J.

Funding: This research was supported by the KIGAM research projects (17-8501; 19-3413).

Acknowledgments: Special thanks to S.W. Kim and H.J. Kim in UGS project (2015-2017) and Reiko Kuwano at Institute of Industrial Science, University of Tokyo, Japan.

Conflicts of Interest: The authors declare no conflict of interest.

\section{References}

1. Kuwano, R.; Sera, R.; Sato, M. Formation of subsurface cavity and loosening due to defeated old sewer pipe. Jpn. Geotech. J. 2010, 5, 219-229. [CrossRef]

2. Sato, M.; Kuwano, R. Influence of location of subsurface structures on development of underground cavities induced by internal erosion. Soils Found. 2015, 55, 829-840. [CrossRef]

3. Waltham, T.; Bell, F.; Culshaw, M. Sinkhole and Subsidence: Karst and Cavernous Rocks in Engineering and Construction; Springer: Berlin, Germany, 2005; p. 384.

4. Gutiérrez, F.; Parise, M.; De Waele, J.; Jourde, H. A review on natural and human-induced geohazards and impacts in karst. Earth Sci. Rev. 2014, 138, 61-88.

5. Guarino, P.; Santo, A.; Forte, G.; De Falco, M.; Niceforo, M. Analysis of a database for anthropogenic sinkhole triggering and zonation in the Naples hinterland (southern Italy). Nat. Hazards 2017, 91, 173-192. [CrossRef]

6. Scotto di Santolo, A.; Forte, G.; Santo, A. Analysis of sinkholes triggering mechanisms in the hinterland of Naples (southern Italy). Eng. Geol. 2018, 237, 42-52. [CrossRef]

7. Sato, M.; Kuwano, R. Effects of buried structures on the formation of underground cavity. In Proceedings of the 18th International Conference on Soil Mechanics and Geotechnical Engineering, Paris, France, 2-6 September 2013; pp. 1769-1772. 
8. Castellazzi, P.; Arroyo-Domínguez, N.; Martel, R.; Calderhead, A.I.; Normand, J.C.L.; Gárfias, J.; Rivera, A. Land subsidence in major cities of Central Mexico: Interpreting InSAR-derived land subsidence mapping with hydrogeological data. Int. J. App. Earth Observ. Geoinform. 2016, 47, 102-111. [CrossRef]

9. Fan, H.; Deng, K.; Ju, C.; Zhu, C.; Xue, J. Land subsidence monitoring by D-InSAR technique. Min. Sci. Tech. 2011, 21, 869-872. [CrossRef]

10. Intrieri, E.; Gigli, G.; Nocentini, M.; Lombardi, L.; Mugnai, F.; Fidolini, F.; Casagli, N. Sinkhole monitoring and early warning: An experimental and successful GB-InSAR application. Geomorphology 2015, 241, 304-314. [CrossRef]

11. Van Schoor, M. Detection of sinkholes using 2D electrical resistivity imaging. J. Appl. Geophys. 2002, 50, 393-399. [CrossRef]

12. Youssef, A.M.; El-Kaliouby, H.M.; Zabramawi, Y.A. Integration of remote sensing and electrical resistivity methods in sinkhole investigation in Saudi Arabia. J. Appl. Geophys. 2012, 87, 28-39. [CrossRef]

13. Zini, L.; Calligaris, C.; Forte, E.; Petronio, L.; Zavagno, E.; Boccali, C.; Cucchi, F. A multidisciplinary approach in sinkhole analysis: The Quinis village case study (NE-Italy). Eng. Geol. 2015, 197, 132-144. [CrossRef]

14. Perez, A.; Nam, B.; Alrowaimi, M.; Chopra, M.; Lee, S.; Youn, H. Experimental Study on Sinkholes: Soil-Groundwater Behaviors Under Varied Hydrogeological Conditions. J. Test. Eval. 2017, 45, 208-219. [CrossRef]

15. Nof, R.N.; Abelson, M.; Raz, E.; Magen, Y.; Atzori, S.; Salvi, S.; Baer, G. SAR interferometry for sinkhole early warning and susceptibility assessment along the Dead Sea, Israel. Remote Sens. 2019, 11, 89. [CrossRef]

16. Nof, R.N.; Baer, G.; Ziv, A.; Raz, E.; Atzori, S.; Salvi, S. Sinkhole precursors along the Dead Sea, Israel, revealed by SAR interferometry. Geology 2013, 41, 1019-1022. [CrossRef]

17. Baer, G.; Magen, Y.; Nof, R.N.; Raz, E.; Lyakhovsky, V.; Shalev, E. InSAR measurements and viscoelastic modeling of sinkhole precursory subsidence: Implications for sinkhole formation, early warning, and sediment properties. J. Geophys. Res. Earth Surf. 2018, 123, 678-693. [CrossRef]

18. Jones, C.E.; Blom, R.G. Bayou Corne, Louisiana, sinkhole: Precursory deformation measured by radar interferometry. Geology 2014, 42, 111-114. [CrossRef]

19. Jeong, S.W.; Kim, S.W.; Yum, B.W.; Kuwano, R. Experimental results on compaction and groundwater level dependent ground subsidence using a small-sized laboratory tank model. J. Korean Soc. Hazard Mitig. 2016, 16, 311-319. [CrossRef]

20. Kuwano, R.; Kohata, Y.; Sato, M. A case study of ground cave-in due to large scale subsurface erosion in old land fill. In Proceedings of the 6th International Conference on Scour and Erosion, Paris, France, 27-31 August 2012; pp. 56-92.

21. Toulkeridis, T.; Rodríguez, F.; Arias Jiménez, N.; Baile, D.S.; Martínez, R.S.; Addison, A.; Carreón Freyre, D.; Mato, F.; Díaz Perez, C. Causes and consequences of the sinkhole at El Trébol of Quito, Ecuador-Implications for economic damage and risk assessment. Nat. Hazards Earth Syst. Sci. 2016, 16, 2031-2041. [CrossRef]

22. Verachtert, E.; Maetens, W.; Van Den Eeckhaut, M.; Poesen, J.; Deckers, J. Soil loss rates due to piping erosion. Earth Surf. Process. Landf. 2011, 36, 1715-1725. [CrossRef]

23. Abdelaziz, A.; Zhao, Q.; Grasselli, G. Grain based modelling of rocks using the combined finite-discrete element method. Comput. Geotech. 2018, 103, 73-81. [CrossRef]

24. Chen, K.T.; Wu, J.H. Simulating the failure process of the Xinmo landslide using discontinuous deformation analysis. Eng. Geol. 2018, 239, 269-281. [CrossRef]

25. Wu, J.H.; Lin, W.K.; Hu, H.T. Post-failure simulations of a large slope failure using 3DEC: The Hsien-du-shan slope, Eng. Geol. 2018, 242, 92-107. [CrossRef]

(C) 2019 by the authors. Licensee MDPI, Basel, Switzerland. This article is an open access article distributed under the terms and conditions of the Creative Commons Attribution (CC BY) license (http://creativecommons.org/licenses/by/4.0/). 